ISSN 0258-7122

Bangladesh J. Agril. Res. 36(2) : 223-230, June 2011

\title{
VARIABILITY AND PERFORMANCE OF SUPERIOR VELVET APPLE (Diospyros discolor) GERMPLASM IN THE HILLY REGION
}

\author{
M. AHMED ${ }^{1}$, S. N. MOZUMder ${ }^{2}$, Z. A. FIROZ ${ }^{3}$ AND S. M. FAISAL ${ }^{4}$
}

\begin{abstract}
The study was conducted at the Hill Tracts Agricultural Research Station, Ramgarh during two years in 2007 and 2008 to evaluate the variability and performance of selected 11 velvet apple germplasm. A lot of variations in different parameters were observed among the trees. The age of plant varied from 7 to 25 years having tree volume $58 \mathrm{~m}^{3}$ to $428 \mathrm{~m}^{3}$. The number of fruits ranged from 42 to 674 per plant with single fruit weight 118 to $283 \mathrm{~g}$. The length and diameter ranged from $6.63 \mathrm{~cm}$ to $7.7 \mathrm{~cm}$ and $5.73 \mathrm{~cm}$ to $8.3 \mathrm{~cm}$, respectively. The maximum edible portion $(68.3 \%)$ was recorded in DD RAM 011, while it was the lowest (47.6\%) in DD RAM 001. The highest TSS\% ranged from $7.28 \%$ to $14.9 \%$. Highest yield per plant $(103.67 \mathrm{~kg})$ was observed in DD RAM 001 and it was lowest in DD RAM $008(5.99 \mathrm{~kg})$. All the parameters showed poor correlation among them. Considering the factors of weight and size, edible portion $\%$, TSS \%, taste, sweetness, and yield per plant, the line DD RAM 011 was found better than others.
\end{abstract}

Keywords: Variability, performance, velvet apple, hilly areas.

\section{Introduction}

Velvet apple (Diospyros discolor) under the family Ebenaceae is an important minor tropical fruit. It is originated from Philippines (Singh, 1998). But it is also found in Assam, Bihar and southern parts of India. In Bangladesh, it has been cultivating since many decades. These fruits are grown well in the district of Kushtia, Jessore, Faridpur, Rajshahi, Barisal, Pirozpur, and Chittagong Hill Tracts region. It is very attractive for its beautiful reddish colour. The surface of the fruit is covered by powdery velvet structure. It is one of the very tasty and beautiful fruits. The texture of the flesh is sandy. Utilization of this crop as a fruit is not very much in Bangladesh. Immature fruits are astringent, while ripe fruits are sweet smelling, delicious and are eaten as dessert fruit. The pulp is sweet and melting. The usual practice is to eat only the pulp. Almost all the people including children like it very much due to its sweet taste and aroma. It is generally used as table purpose fruits. Fruits are nutritionally rich which (per $100 \mathrm{~g}$ of edible portion) contain calories 113 , water $69.6 \mathrm{~g}$, carbohydrates $26.6 \mathrm{~g}$, fibre $1.5 \mathrm{~g}$, fat $0.1 \mathrm{~g}$. protein $1.4 \mathrm{~g}$, minerals $0.8 \mathrm{~g}$, calcium $58 \mathrm{mg}$ (Mondal, 2000). Green fruits have medicinal value as the juice of immature fruit is used to cure

${ }^{1}$ Scientific Officer (Horticulture), ${ }^{2 \& 4}$ Senior Scientific Officer (Horticulture), ${ }^{3}$ Principal Scientific Officer, HTARS, Bangladesh Agricultural Research Institute (BARI), Ramgarh, Khagrachari Hill District, Bangladesh. 
ulcer and dysentery (Rashid et al., 1987). It is of medium vigorous growth and makes a desirable ornamental shade tree (Wester, 2009). These fruit is propagated by seed and grafts. But unfortunately, there is no good and released variety of velvet apple in Bangladesh. There is some germplasm, rarer than the red, with yellowish to light brown fruits, the flesh of which is cream coloured and sweeter, and less astringent (Wester, 2009). Fruits produced in different or even in the same areas, different types of variation were observed. Some of the variations are genetic and some of them are environmental. Environmental variation could be manipulated but genetic variations are persistent. Wide genetic variations of velvet apple germplasm were observed in the hilly areas. There are more than 30 germplasm available at HTARS, Ramgarh. All plants showed variability. Hence, the study was undertaken to evaluate the selected germplasm for identifying the most desirable line for hilly areas.

\section{Materials and Method}

The experiment was conducted at HTARS, Ramgarh during two years in 2007 and 2008. After primary observation of 30 fruiting trees, 11 germplasm were selected having better performance and diversity. The 11 selected germplasm which was included in this study were DD RAM 001, DD RAM 002, DD RAM 003, DD RAM 004, DD RAM 005, DD RAM 006, DD RAM 007, DD RAM 008, PD RAM 009, DD RAM 010, and DD RAM 011 to select the advanced velvet apple line. The plants were fertilized with cowdung $(30 \mathrm{~kg})$, urea $(1.2 \mathrm{~kg})$, TSP (1.5 kg), MP (1.2 kg), and gypsum (300 g) in two equal installments every year i.e. one in May and another in October 2006 and 2007. Insect and diseases infestation were minimum so, no control measures were applied. Ages of the plants were collected from the previous records of the station and information from the old workers. Base girth of the main trunk was measured at a height of $15 \mathrm{~cm}$ from ground level. Data on base girth, plant height, length of main stem, main branches per plant, plant spread (north-south and east-west) were recorded at the time of first harvest in every year and mean of the two years were presented in the Table. The accession number of germplasm was determined according to the first alphabet of genus and species along with the first three alphabets of the location of the research station. Here Diospyros discolor indicated by DD and RAM was taken from Ramgarh. Tree volume was calculated by using the formula of Castle (1983) with slight modification. Tree volume $\left(\mathrm{m}^{3}\right)=\mathrm{II} / 6 \mathrm{xheightx}(2 \mathrm{r})^{2}$, where $(2 \mathrm{r})=($ East-West spread + North-South spread)/2. All fruits were considered for number of fruits, mean fruit weight, and yield per plant. Five fruits from each plant were randomly selected for evaluation of individual fruit performance and fruit quality. Fully mature fruits were harvested from the plant and fruit characteristics were recorded after ripening of the fruits and the mean data were calculated and two years' mean data were presented in Tables. Mean, maximum, minimum, and standard deviation were 
calculated from two years' mean data using MS-Excel and correlation and hierarchical cluster analysis was conducted using SPSS program.

\section{Results and Discussion}

The age of plant of different lines varied considerably ranging from 7 to 25 years (Table 1). The maximum age of plant was recorded in the line DD RAM 001 and DD RAM 002 having 25 years of age, while DD RAM 008 was found to be the youngest plant ( 7 years). The base girth of the plants ranged from $29 \mathrm{~cm}$ (DD RAM 008) to $98 \mathrm{~cm}$ (DD RAM 001). The size of plants also differed considerably. The maximum number of main branches (13) per tree was recorded in the lines DD RAM 001 and DD RAM 008, which was followed by that of DD RAM 003 (8). The maximum plant height $(10.73 \mathrm{~m})$ was recorded in DD RAM 004 followed by DD RAM $003(10.54 \mathrm{~m})$ and the lowest $(5.80 \mathrm{~m})$ in DD RAM 007. It was found that height of plants of most of the lines ranged between 5.8 and $10.73 \mathrm{~m}$. The North-South and East-West spreading of the tree ranged from 3 to $8.04 \mathrm{~m}$ and 2.92 to $10.39 \mathrm{~m}$, respectively. The mean N-S and E-W spreading of the tree was $5.70 \mathrm{~m}$ and $6.23 \mathrm{~m}$, respectively. Tree volume ranged from $58 \mathrm{~m}^{3}$ (DD RAM 009 and DD RAM 011) to $428 \mathrm{~m}^{3}$ (DD RAM 003) with an average of $180.41 \mathrm{~m}^{3}$ having large (119.97) standard deviation.

Table 1. Growth characteristics of 11 velvet apple germplasm*.

\begin{tabular}{|c|c|c|c|c|c|c|c|c|}
\hline \multirow{2}{*}{ Acc. no. } & \multirow{2}{*}{$\begin{array}{c}\text { Age of } \\
\text { plant }\end{array}$} & \multirow{2}{*}{$\begin{array}{l}\text { Base } \\
\text { girth } \\
(\mathrm{cm})\end{array}$} & \multirow{2}{*}{$\begin{array}{c}\text { Length of } \\
\text { main } \\
\text { stem }(\mathrm{m})\end{array}$} & \multirow{2}{*}{$\begin{array}{c}\text { Main } \\
\text { branches } \\
\text { /plant }\end{array}$} & \multirow{2}{*}{$\begin{array}{l}\text { Plant } \\
\text { height } \\
(\mathrm{m})\end{array}$} & \multicolumn{2}{|c|}{ Spread (m) } & \multirow{2}{*}{$\begin{array}{c}\text { Tree } \\
\text { volume } \\
\left(\mathrm{m}^{3}\right)\end{array}$} \\
\hline & & & & & & E-W & $\mathrm{N}-\mathrm{S}$ & \\
\hline DD RAM 001 & 25 & 98 & 0.77 & 13 & 9.50 & 8.33 & 7.82 & 324 \\
\hline DD RAM 002 & 25 & 80 & 2.10 & 7 & 9.00 & 7.90 & 5.55 & 213 \\
\hline DD RAM 003 & 20 & 78 & 1.94 & 8 & 10.54 & 10.39 & 7.23 & 428 \\
\hline DD RAM 004 & 20 & 74 & 1.40 & 2 & 10.73 & 6.15 & 7.05 & 245 \\
\hline DO RAM 005 & 18 & 44 & 2.05 & 6 & 8.00 & 4.60 & 5.03 & 97 \\
\hline DD RAM 006 & 20 & 74 & 3.11 & 7 & 10.05 & 6.14 & 5.00 & 163 \\
\hline DD RAM 007 & 18 & 78 & 1.78 & 3 & 5.80 & 9.12 & 8.04 & 224 \\
\hline DD RAM 008 & 7 & 29 & 1.92 & 13 & 7.35 & 4.32 & 5.29 & 89 \\
\hline DD RAM 009 & 8 & 40 & 2.23 & 3 & 10.12 & 2.92 & 3.68 & 58 \\
\hline DD RAM 010 & 10 & 48 & 1.88 & 5 & 6.38 & 5.11 & 5.00 & 85 \\
\hline DD RAM0I1 & 11 & 55 & 2.18 & 2 & 10.5 & 3.5 & 3.00 & 58 \\
\hline Mean & 16.55 & 63.45 & 1.94 & 6.27 & 8.91 & 6.23 & 5.70 & 180.41 \\
\hline $\operatorname{Max}$ & 25 & 98 & 3.11 & 13 & 10.73 & 10.39 & 8.04 & 428 \\
\hline Min & 7 & 29 & 0.77 & 2 & 5.8 & 2.92 & 3 & 58 \\
\hline STDV & 6.49 & 21.30 & 0.57 & 3.93 & 1.76 & 2.43 & 1.65 & 119.97 \\
\hline
\end{tabular}

* Mean data of 2007 and 2008 
The size of fruits also differed considerably (Table 2). The maximum length and diameter of fruits $7.7 \mathrm{~cm}$ and $8.3 \mathrm{~cm}$ were recorded in DD RAM 002 and DD RAM 011 and the lowest $6.63 \mathrm{~cm}$ and $5.73 \mathrm{~cm}$, respectively. It was found that length and diameter of fruits of most of the lines ranged between 6.63 and $7.7 \mathrm{~cm}$ and $5.73 \mathrm{~cm}$ and $8.3 \mathrm{~cm}$. Most fruits develop without seeds and are flattenedglobose in shape. Those that develop seeds, however, are elongated and very similar in shape to the apple. The soft mealy flesh is whitish and aromatic (USDA, 2009). The percentage of edible portion is considered to be an important criterion in judging quality of fruits. The consumers always prefer higher edible portion. The highest percentage of edible portion (68.3\%) was recorded in DD RAM 011, which was closely followed by DD RAM $004(57.80 \%)$ and DD RAM 005 (56.84\%). The lowest edible portion (47.60\%) was obtained from DD RAM 001. High TSS\% is an important criterion for selection of good quality fruit. The highest TSS\% (14.9\%) was found in DD RAM 011, which was followed by that of DD RAM 001 (9.95\%), DD RAM 003 (9.44\%), DD RAM 005 (9.46\%), DD RAM 007 (9.50\%), DD RAM 008 (9.39\%) and the lowest (7.28\%) in DD RAM 002 having 9.44 mean and 1.99 standard deviation.

Table 2. Fruit characteristics of 11 velvet apple germplasm.

\begin{tabular}{l|l|l|c|c|c|c|c|c}
\hline \multirow{2}{*}{ Acc. no. } & \multicolumn{2}{c}{ Size of fruit $(\mathrm{cm})^{*}$} & \multicolumn{3}{c}{ Edible portion $(\%)$} & \multicolumn{3}{c}{ TSS $(\%)$} \\
\cline { 2 - 9 } & Length & Diameter & 2007 & 2008 & Mean & 2007 & 2008 & Mean \\
\hline DD RAM 001 & 6.96 & 6.92 & 47.16 & 48.04 & 47.60 & 10.82 & 9.08 & 9.95 \\
DD RAM 002 & 7.70 & 6.72 & 49.47 & 55.19 & 52.33 & 7.00 & 7.56 & 7.28 \\
DD RAM 003 & 7.35 & 6.53 & 49.34 & 47.66 & 48.50 & 10.0 & 8.88 & 9.44 \\
DD RAM 004 & 6.97 & 6.69 & 56.98 & 58.62 & 57.80 & 9.36 & 8.24 & 8.80 \\
DO RAM 005 & 6.92 & 6.88 & 54.02 & 59.66 & 56.84 & 9.96 & 8.96 & 9.46 \\
DD RAM 006 & 7.50 & 6.53 & 55.60 & 51.31 & 53.45 & 9.64 & 7.91 & 8.78 \\
DD RAM 007 & 7.11 & 5.73 & 50.55 & 52.53 & 51.54 & 10.0 & 9.00 & 9.50 \\
DD RAM 008 & 6.63 & 6.39 & 47.75 & 50.17 & 48.96 & 9.94 & 8.84 & 9.39 \\
DD RAM 009 & 6.92 & 6.25 & 51.18 & 46.57 & 48.87 & 7.76 & 7.41 & 7.59 \\
DD RAM 010 & 6.91 & 5.82 & 49.39 & 57.83 & 53.61 & 9.56 & 7.88 & 8.72 \\
DD RAM 011 & 6.90 & 8.30 & 68.28 & 68.32 & 68.3 & 14.8 & 15 & 14.9 \\
\hline Mean & 7.08 & 6.61 & 52.70 & 54.17 & 53.44 & 9.89 & 8.98 & 9.44 \\
Max. & 7.7 & 8.3 & 68.28 & 68.32 & 68.3 & 14.8 & 15 & 14.9 \\
Min. & 6.63 & 5.73 & 47.16 & 46.57 & 47.6 & 7 & 7.41 & 7.28 \\
STDV & 0.31 & 0.68 & 6.05 & 6.55 & 5.96 & 1.96 & 2.09 & 1.99 \\
\hline
\end{tabular}

* Mean data of 2007 and 2008.

The number of fruits ranged from 42 to 674 per plant (Table 3). The maximum number of fruits per plant was recorded in DD RAM 007 (674) followed by DD RAM 004 (609) and the lowest (42) in DD RAM 008. The 
single fruit weight in different plants varied considerably ranging from 118 to $283 \mathrm{~g}$. The highest fruit weight (283 g) was recorded in the line DD RAM 011 followed by that of DD RAM $005(185.8 \mathrm{~g})$. Yield per plant ranged from $5.99 \mathrm{~kg}$ (DD RAM 008) to $103.67 \mathrm{~kg}$ (DD RAM 001) with an average of $60.81 \mathrm{~kg}$ having 40.86 standard deviation. The highest fruit yield $(103.67 \mathrm{~kg})$ was recorded in the line DD RAM 001 and the lowest (5.99 kg) in DD RAM 008.

Table 3. Yield characteristics of 11 velvet apple germplasm.

\begin{tabular}{l|llll|l|l|l|l|l|}
\hline \multirow{2}{*}{ Acc. no. } & \multicolumn{3}{c}{ Fruits/plant } & \multicolumn{3}{c}{ Single fruit wt. (g) } & \multicolumn{3}{c}{ Yield/ plant $(\mathrm{kg})$} \\
\cline { 2 - 11 } & 2007 & 2008 & Mean & 2007 & 2008 & Mean & 2007 & 2008 & Mean \\
\hline DD RAM 001 & 775 & 389 & 582 & 180.9 & 172.6 & 176.8 & 140.20 & 67.14 & 103.67 \\
DD RAM 002 & 739 & 443 & 591 & 187.0 & 151.6 & 169.3 & 138.19 & 67.16 & 102.68 \\
DD RAM 003 & 618 & 380 & 499 & 168.9 & 137.4 & 153.2 & 104.38 & 52.21 & 78.29 \\
DD RAM 004 & 665 & 552 & 609 & 199.6 & 136.2 & 167.9 & 131.03 & 75.08 & 103.05 \\
DD RAM 005 & 157 & 51 & 104 & 219.9 & 151.6 & 185.8 & 34.52 & 7.73 & 21.13 \\
DD RAM 006 & 419 & 481 & 450 & 186.9 & 130.4 & 158.7 & 78.31 & 62.72 & 70.52 \\
DD RAM 007 & 623 & 724 & 674 & 135.0 & 100.9 & 118.0 & 84.11 & 73.05 & 78.58 \\
DD RAM 008 & 30 & 53 & 42 & 140.8 & 146,4 & 143.6 & 4.22 & 7.76 & 5.99 \\
DD RAM 009 & 38 & 75 & 57 & 159.6 & 120.0 & 139.8 & 6.06 & 9.00 & 7.53 \\
DD RAM 010 & 113 & 72 & 93 & 106.0 & 130.4 & 118.2 & 11.98 & 9.39 & 10.69 \\
DD RAM 011 & 281 & 329 & 305 & 305 & 261 & 283 & 85.71 & 87.84 & 86.77 \\
\hline Mean & 405 & 323 & 364 & 180.9 & 149.0 & 164.9 & 74.43 & 47.19 & 60.81 \\
Max & 775 & 724 & 674 & 305 & 261 & 283 & 140.2 & 87.84 & 103.67 \\
Min & 30 & 51 & 42 & 106 & 100.9 & 118 & 4.22 & 7.73 & 5.99 \\
STDV & 290.96 & 230.57 & 249.65 & 52.22 & 41.55 & 44.94 & 52.75 & 31.88 & 40.86 \\
\hline
\end{tabular}

Table 4. Qualitative characteristics of 1 velvet apple germplasm.

\begin{tabular}{lllllll}
\hline Acc. no. & Taste & Sweetness & Skin color & Flavor & Bearing \\
\hline DD RAM 001 & Very good & Very sweet & Reddish & Pleasant & Seasonal \\
DD RAM 002 & Good & Sweet & Reddish & Pleasant & Seasonal \\
DD RAM 003 & Good & Sweet & Light reddish & Pleasant & Seasonal \\
DD RAM 004 & Good & Very sweet & Light reddish & Pleasant & Seasonal \\
DD RAM 005 & Very good & Very sweet & Light reddish & Pleasant & Seasonal \\
DD RAM 006 & Good & Sweet & Reddish & Pleasant & Year round \\
DD RAM 007 & Excellent & Very sweet & Reddish & Pleasant & Seasonal \\
DD RAM 008 & Good & Very sweet & Light reddish & Pleasant & Year round \\
DD RAM 009 & Good & Sweet & Reddish & Pleasant & Seasonal \\
DD RAM 010 & Good & Sweet & Reddish & Pleasant & Seasonal \\
DD RAM 011 & Excellent & Very sweet & Reddish & Pleasant & Seasonal \\
\hline
\end{tabular}


The skin colour in most of the fruits was light reddish to reddish (Table 4). The fruits of the lines DD RAM 007, DD RAM 008, and DD RAM 011 were found very tasty and sweet. Some germplasm had excellent taste and very sweet fruits but some are inferior to them. The germplasm were pleasant in flavour. Most of them are of seasonal bearing habit, some are year round bearing habit. The study indicated that there were wide variations among the lines, which would provide a good scope in developing some potential lines of this fruit. However, considering the factors of weight and size, \% edible portion, TSS\%, taste, sweetness, and yield per plant, the line DD RAM 011 was found superior to others.

Table 5. Pearson Correlations among different parameters of velvet apple germplasm.

\begin{tabular}{l|c|c|l|l|l|l}
\hline Characters & $\begin{array}{c}\text { Single } \\
\text { fruit wt }\end{array}$ & $\begin{array}{c}\text { Fruit } \\
\text { length }\end{array}$ & Fruit dia. & $\begin{array}{c}\text { Edible } \\
\text { portion (\%) }\end{array}$ & TSS(\%) & Yield/plant \\
\hline Fruits/plant & .022 & .592 & .028 & -.045 & -.025 & $.924^{* *}$ \\
Single fruit wt & & -.066 & $.991^{* *}$ & $.789^{* *}$ & $.808^{* *}$ & .371 \\
Fruit length & & & -.054 & -.126 & -.346 & .540 \\
Fruit dia & & & & $.715^{*}$ & $.765^{*}$ & .386 \\
Edible portion & & & & & $.727^{*}$ & .205 \\
$(\%)$ & & & & & .218 \\
TSS(\%) & & & & & & \\
\hline
\end{tabular}

** Correlation is significant at the 0.01 level (2-tailed).

* Correlation is significant at the 0.05 level (2-tailed).

Fruits of DD RAM 011 were large, sweet taste, attractive reddish colour having higher yield potentiality that proves its superiority over other lines.

\section{Correlation among 7 characters of 11 velvet apple germplasm}

The 2-tailed Pearson correlation co-efficient values and level of significance among 7 yield attributing characters of 11 velvet germplasm are presented in Table 5. A number of correlations were significant among the different parameters of velvet apple. There was a significant positive correlation $\left(r^{2}=\right.$ $0.924 * *$ ) observed in number of fruits per plant and yield. Number of fruits per plant positively correlated with single fruit weight (0.022), length (0.592), and diameter of fruit (0.028), while edible portion (\%) (-0.045) and TSS (\%) (-0.025) had negative correlation. Fruit yield per plant showed positive correlation with single fruit weight $(0.371)$, length of fruit $(0.540)$, diameter of fruit (0.386), edible portion (\%) (0.205), and TSS(\%) (0.218). Total soluble solid (TSS\%) had significant positive correlation with single fruit weight $\left(0.808^{* *}\right)$, fruit diameter $\left(0.765^{*}\right)$ and edible portion $(\%)\left(0.727^{*}\right)$, while it showed negative correlation with the number of fruits and fruit length. This indicated that larger fruits are sweeter than small fruits. The better correlation among the parameters indicated 
the diversified variability in velvet apple which might be helpful for selection of superior lines.

\section{Dendrogram}

\section{Fig.1 Dendrogram using average linkage (between groups)}

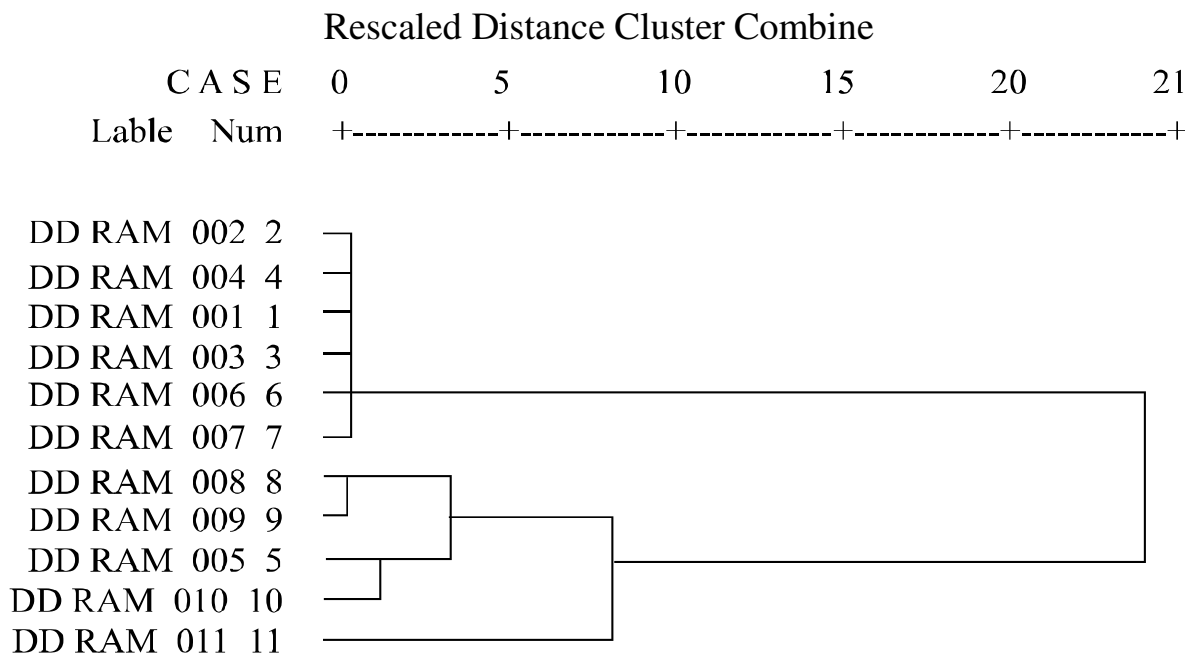

\section{Hierarchical cluster analysis}

Fig 1. showed the Hierarchical cluster analysis using different yield attributing and other characters of 11 velvet apple germplasm. Here, the dendrogram using single linkage showed three divisions or cluster of germplasm. Cluster one having 6 germplasm, 4 in cluster 2, which have minimum distances among them, while only one germplasm represented the cluster three. The cluster 1 which includes 6 germplasm, such as DD RAM 001, DD RAM 002, DD RAM 003, DD RAM 004, DD RAM 006, and DD RAM 007 which seems to be higher yielder and maximum number of fruits better than second cluster. The second cluster included 4 germplasm, which were DD RAM 005, DD RAM 008, DD RAM 009 and DD RAM 010 that showed weaker yield performances. The third cluster having only one germplasm (DD RAM 011), which had the larger fruits, highest TSS content and maximum edible portion which differed from the other germplasm. The germplasm DD RAM 011 seems to be superior among the evaluated germplasm.

\section{References}

Castle, S. W. 1983. Growth, yield and cold hardiness of seven years " Bears" Lemon trees on twenty seven root stocks. Proc. Fla, State Hort. SOC. 96: 23-25.

Mondal, M. F. 2000. Production and Storage of Fruits (in Bangla). Mrs. Afia Mondal, BAU Campus, Mymensingh. 2202. p. 212. 
Rashid, M. M., M. A. Kadir, M. M. Hossain. 1987. Bangladesher Phal (in Bangla). Bangladesh Packing Press Limited. Tejgaon, Dhaka. p. 166.

Singh, R. 1998. Fruits. National Book Trust, A-5, Green Park, New Delhi, India. p. 200. USDA.2009. httpllwww.npdc.usda.gov (Viewed : 29/10/2009).

Wester, P. J. 2009. www.desert-tropicals.com. (Viewed : 29/10/2009). 